\title{
Study of cutaneous infections in diabetic patients
}

\author{
Namita J. Padwal, Lalana Kalekar, Dhammadeep Humane \\ ** Assistant Professor, * Residant, Department of medicine, Lokmanya Tilak Municipal medical college Sion \\ Mumbai.
}

\begin{abstract}
Diabetes is a disease of multisystem complication. Skin manifestation including various infective and non infective lesions are very common. A study was conducted in a tertiary care institute to evaluate different skin infections seen in diabetic patients.

Materials and methods: All diabetic patients attending outpatient services or indoor admitted diabetic patients in the institute over one and half years were screened for cutaneous infection. Correlation of their overall glucose control with outcome of infection was done in terms of duration of type of treatment required ,outpatient or indoor hospital stay required, surgical intervention, morbidity and mortality.

Result: 100 diabetics with skin infections and 50 age and sex matched controls were included in the study. Cutaneous infections were present in almost every part of body in case group. Various infections were boils, carbuncle, cellulitis, Diabetic foot ulcers, candidiasis, dermatophytes, gangrene, Fournier's gangrene, malignant otitis externa, mucormycosis, herpes zoster, necrotysing fasciitis and pyoderma.

Discussion and conclusions: The factors affecting wound healing and response to treatment were size and site of wound, time lag for treatment, presence of anaemia, raised HBAlc and presence of systemic diseases. Five patients expired during follow up period of 6 months. These were 4 cases of foot ulcers and one case of mucormycosis. Those succumbed were having multiple systemic complications. Most common site of infection is the lower limbs in diabetes mellitus. Infection of genitalia or intertigous parts are difficult to treat.
\end{abstract}

\section{Introduction}

The association of certain diseases of skin with diabetes has been fairly well recognised with an incidence ranging from $11.4 \%$ to $71 \%$.Infact skin problems are sometimes the first sign that a person has diabetes. Macro vascular and micro vascular diseases may result in compromised local circulation or sensory neuropathy which leads to delayed response to infection and impaired wound healing. ${ }^{1}$

We conducted a prospective observational study to observe the association of skin infections in diabetic population seeking treatment from an urban tertiary care centre.

\section{Materials and methods}

An unicenric observational open study was conducted in an urban tertiary care centre and general hospital to study pattern of cutaneous infection in diabetic patients. All diabetic patients attending outpatient services or indoor admitted diabetic patients were screened for cutaneous infection. The patients were studied for site of infection, systemic complications associated with cutaneous infection, their metabolic parameters like blood glucose control were studied. Correlation of their overall glucose control with outcome of infection was done in terms of duration of type of treatment required, outpatient or indoor hospital stay required, surgical intervention ,morbidity and mortality. These patients were compared with 50 age and sex matched controls without skin infections for metabolic control.

\section{Results}

Altogether 150 patients were included in the study. 100 cases and 50 controls of diabetic patients were studied. $45 \%$ were female patients. Age was ranging between 30 t0 70 years with maximum patients between 50 to 60 years in both case and control groups.93 patients in study group and 48 in control group were having BMI >25. Mean BMI was 27.87 with SD 3.11.(Table 1)

Duration of diabetes was ranging from recently detected to more than 10 years.( Table 2) Primary complaints in study group were fever, nonhealing wounds, boils and itching.(Table3) Various infections were boils, carbuncle, cellulitis, Diabetic foot ulcers, candidiasis, dermatophytes ,gangrene, Fournier's gangrene, malignant otitis externa,mucormycosis, herpes zoster,necrotysing fasciitis and pyoderma. (Table 4) Cutaneous infections were present in almost every part of body in case group.(fig1). Only 9 patients were treated on opd basis, rest all were indoor admissions. Indoor stay was ranging from 7 days to 28 days. Mean duration of hospital was 14 days. Most of the cases were of foot ulcer. Peripheral pulses were felt in almost all cases confirmed by Doppler study .Anaemia i.e., $\mathrm{Hb}<11 \mathrm{gm} \%$ was present in 72 cases and 14 controls.(Table5) Leucocytosis was present in almost all cases.(Table 6) HbA1C was ranging from 6.5 to $>13$ in cases as against 
controls who were having 6.5 to 7.4. Maximum patients in case group were having HbA1C between 7.5 to 8.9. Mean HBA1c in case group being 8.29 with SD of 1.98. (Table 7)

Nine patients had diabetic ketoacidosis. Pus culture grew Staphylococcus both MRSA and MSSA, Acinatobactor, Candida, E. Coli and Klebsiella. No growth was seen in 60 cases.( Table 8 ) 21 patients in case group and 3 patients in control group were having retinopathy. 5 patients in case group and 3 patients in control group had neuropathy symptoms but monofilament test was positive only in 3 cases and none in controls.(Table 9)53 patients were not on any treatment at the time of enrolment. Rest all patients were either on oral hypoglycaemic agents or Insulin. Mean fasting blood glucose was $140 \mathrm{gm} \%$ in cases and $96 \mathrm{gm} \%$ in controls., 52 were treated conservatively, 15 patients required amputation ,16 required debridement and 17 required excision biopsy. 5 patients expired.

\section{Discussion}

Diabetes is a disease of multisystem complication. Skin manifestation including various infective and non infective lesions are very common. Persistent chronic hyperglycemia affects the immune system of the body. It has been postulated that chronic hyperglycemia induce the polymorphonuclear cells in chronic hyper exited state. These PMNL cells then release neutrophil granules like myeloperoxidase and elastase. Due to this PMML cells remain in burnt out state or tolerant phase which respond less severely to incoming infection. These leukotrines further lead to vascular damage which by reducing blood supply of the tissues decrease clearance of organisms at the site of infections. ${ }^{2}$ In previous studies the skin manifestations were seen mostly in patients with disease duration of more than one year. $\left({ }^{3,4,5}\right)$ In present study maximum cases were ranging from 30 to 50 years of age. The duration of diabetes was ranging from few days to more than 10 years. As the diabetic status duration increases there is a nonenzymatic lycoselation of dermal collagen and mucopolysaccharides. ${ }^{(6)}$ Obesity was present in $88 \%$ of cases. $5 \%$ patients were having BMI $>35$. Many of these obese patients were having ulcer over lower limbs and celllitis.

Classical signs of infections are generally absent in diabetics. This may be due to associated neuropathy or vascular compromise. ${ }^{(7,8)}$ Fever was present in patients with deeply infected wounds and cellulites. Itching was seen in patients with inner thigh, axillae and back fungal infections. An old lady presented with stroke and detected to have multiple boils over back. Patients presented with chronic renal failure and detected to have diabetic foot injury which was unnoticed by the patient.

The factors affecting wound healing and response to treatment were size and site of wound, time lag for treatment, presence of anaemia ( $\mathrm{p}$ value $<0.05$ in our study), uncontrolled blood sugar as seen by raised HBA1c ( $\mathrm{p}$ value <0.05) and presence of systemic diseases as renal failure, neuropathy and nephropathy. $(9,10,11,12,13,14,15,16)$ This affected the in hospital stay of the patients as well as their outcome. Presence of peripheral arterial disease and anaemia affected their wound healing duration. Anaemia delayed wound healing by decreasing tissue oxygenation. Also iron deficiency may decrease oxygen delivery and increase susceptibility to infection. ${ }^{(17) .}$ Leucocytosis was observed in 88 patients. Mean WBC count was $20050 / \mathrm{cm} 3$ with SD of 7.81 . With control of infection lecocytosis decreased. Poorly controlled hyperglycemia adversely affects the ability of leucocytes to destroy invading bacteria and to prevent the harmful proliferation of commonsals in the body. ${ }^{(18)}$

In present study raised $\mathrm{HbA} 1 \mathrm{c}$ was associated with poor control of infection. The $\mathrm{p}$ value was less than 0.05 which was statistically significant. Mean HBA1c was $8.39 \%$ and there were 1.3 wound per individual (130 wounds total) measured by Multiple linear regression model controlling method for clustering of wounds in individuals and other common clinical variables using number of wounds and duration for healing of wounds. For each $1.0 \%$ increase in $\mathrm{HbA1c}$, the daily wound area healing rate is decreased by $0.034 \mathrm{~cm}^{2} / \mathrm{day}^{(19)}$ (Table10)

Ketosis impairs the inflammatory response and permits tissue invasion of the organisms. Acidosis and high blood glucose increase the growth rate of microorganisms. In our study $9 \%$ patients were detected to have ketoacidosis at the time of admission. The site of infection were perineum (32\%) and lower extremities $(22 \%)$. One case of mucormycosis had ketoacidosis who succumbed even after Amphotericin treatment.

Pattern of causative organism was same as that of nondiabetic patients except mucormycosis which was seen in diabetic patients only. Culture sentivity is useful only for selection of antibiotics. Mean duration of antibiotic therapy was 12 days. Diabetic foot cases required parental antibiotics for 2-3 weeks if the bone is infected. The infection was polymicrobial in necrotising fasciitis(4\% case) involving perineum and lower extremities. $^{(20,21)}$

It was observed that $35 \%$ of cases among retinopathy, 25\% among peripheral artery disease ,20\% among nephropathy and $28 \%$ among neuropathy had nonhealing or infected wound on follow up. Rest all patients showed good wound healing but predominantly due to very tight blood glucose control. Noncompliance of anti diabetics was major contributing factor for uncontrolled blood sugar. ${ }^{(22,23)} 52 \%$ of patients were treated conservatively for skin infection. $16 \%$ required debridement. $17 \%$ cases of foot ulcers required amputation.5 required repeated amputation at higher level due to nonhealng ulcer. $10 \%$ case received antifungals like 
fluconazole systemic or just local application. Only one received Amphotericin B for mucormycosis. 5\% were treated with Cefritrioxone, $2 \%$ with Imipenam and Cilastin. 21\% received Meropenam. Piperacillin Tazobactom was given to $29 \%$ and Vancomycin to $16 \%$ cases. All isolates of Staphylicoccus MRSA and MSSA were sensitive to Vancomycin and Linezolid.

5 patients expired during follow up period of 6 months. These were 4 cases of foot ulcers and one case of mucormycosis. Those succumbed were having multiple systemic complications.

\section{Conclusions}

Most common site of infection is the lower limbs in diabetes mellitus. Infection of genitalia or intertigous parts are difficult to treat. Hygiene is important for prevention of skin infections as gram positive organisms are the causative agents. ${ }^{(24)}$ Overall blood sugar control as shown as HbA1c and anaemia correlated with prolonged infections in our study. Neuropathy has a role in delayed wound healing but that could not be proved in our study as neuropathy was assessed by monophilament test only. EMG NCV study might confirm the evidence. However autonomic neuropathy could be one of the factors associated with presence of inection all over the body especially back and groin.

\section{References}

[1]. Hattemn SV,Boots MA,Thio HB.Skin manifestations of diabetes. Cleveland Clin J Med 2008;75:772-87.

[2]. Helene T.C., Calvet, Thanast.Yoshikava.Infections in diabetes, Inf. Dis.Clin.North America,2001;407-19.

[3]. Nigam P.K.,Pande S.,Pattern of dermatosis in diabetes.Indian J.DermatolVenerol Leprol2003;69:83-85.

[4]. Mahajan S., Koranne RV,Sharma SK. Cutaneous manifestations of diabetes mellitus. Indian J.DermatolVenerol Leprol2003;69:105-108

[5]. Bedi BMS,Kandhari KC.Diabetes or prediabetecs and dermatosis. J.Asso.Phys.Ind 1965;13:809-810

[6]. Altereas I, Saryt E;Prevalence of Pathogenic fungi in the toe webs and toe-nails of diabetic patients. Mycropathologia 1979; 67:157159.

[7]. Smith JP,Burus TW,Leigh CC. Diabetes mellitus and lipoatrophy. South Med J.1990:83:573-576

[8]. Braverman IM. Skin signs of systemic disease. Philadelphia: WB Saunders,1981:p.654-664.

[9]. Meurer M, Szeimies RM. Diabetes mellitus and skin diseases. Curr Prob Dermatol 1991;20:11-23

[10]. Petroz JW, Warthan TL.malignant external otitis.Arch Dermatol 1974; 110: 258-260

[11]. Huntley AC. Cutaneous manifestations of diabetes mellitus. Dermatol clin 1989; 531-546.

[12]. Grunfeld C. Diabetes foot ulcers: etiology, treatment and prevention. Adv Intern Med 1991; 37:103-132.

[13]. Renell WS, Bamisedun O. Diabetic cutaneous microangiopathy. Am J. Med 1992; 93: 611-618

[14]. Braverman IM, Sibley J, Keh A. Ultrastructuralanalysis of the endothelial - pericyte relationship in diabetic cutaneous vessels. J. Invest Dermatol 1990; 95:147-153

[15]. Bleich HL, Boro ES. Diabetic polyneuropathy the importance of insulin deficiency , hyperglycemia and alteration in myoinositol metabolism in its pathogenesis. N. Engl J Med 1976; 295; 1416-1420

[16]. Huntly AC. The cutaneous manifestation of diabetes mellitus. J. Am. Acad Dermatol 1982; 7:427-455

[17]. Hugo NE, Thompson LW,Zook EG et al. Effect of chronic anaemia on the tensile strength of healing of wounds. Surgery 1969;66:741.

[18]. O Dell ML(1999). Skin and wound infections : An overview.Amer.Fam.Phys.,57(10):1-12.

[19]. Apelqvist J,Bakker K,van Houtum WH,Schaper NC. International working group on the Diabetic Foot. Diabetes Metab Res Rev.2008;2 Suppl 1:5116-93.

[20]. Tentolouris N. Jude E.H., Smirnof I.,Knoeles E.A., Boulton A.J.M.:Methicillin resistant Staphylococcus aureus: an increasing problem in a diabetic foot clinic. Diabetic Med 16:767-771, 1999.

[21]. Mohanty S.,Kapil A, Dhawan B, Das BK. Bacteriological and antimicrobial susceptibility profile of soft tissue infection from North India. Indian J of Med Sci.2004;58:10-5

[22]. Rao GS,Pai GS. Cutaneous manifestations of Diabetes mellitus: a clinical study. Indian J Dermatol Veneral Leprol 1997;63:232234

[23]. Bhat YJ, Gupta V, Kudyar RP. Cutaneous manifestations of diabetes mellitus. Int J Diab Dev Ctries 2006; 26: 152-155

[24]. Burie JP, Odds FC, Lee W et al. Outbreak of systemic Candida albicans in an intensive care unit caused by cross infection. Br. Med. J 1985; 290: 746-8.

Table 1 BMI

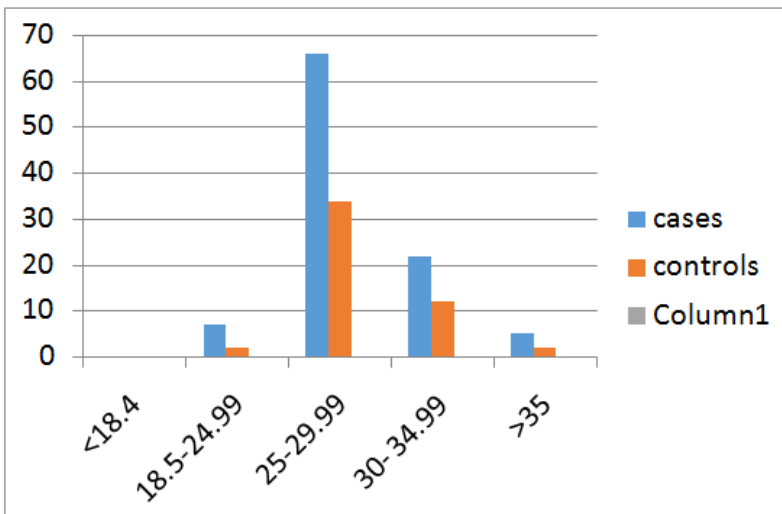




\begin{tabular}{|l|l|l|}
\hline Duration of diabetes mellitus in years & cases & controls \\
\hline Rescent & 7 & 5 \\
\hline 1 to 5 & 24 & 16 \\
\hline$>5$ & 69 & 29 \\
\hline
\end{tabular}

Table 2 Duration of diabetes

Table 3 Symptoms

\section{$\%$}

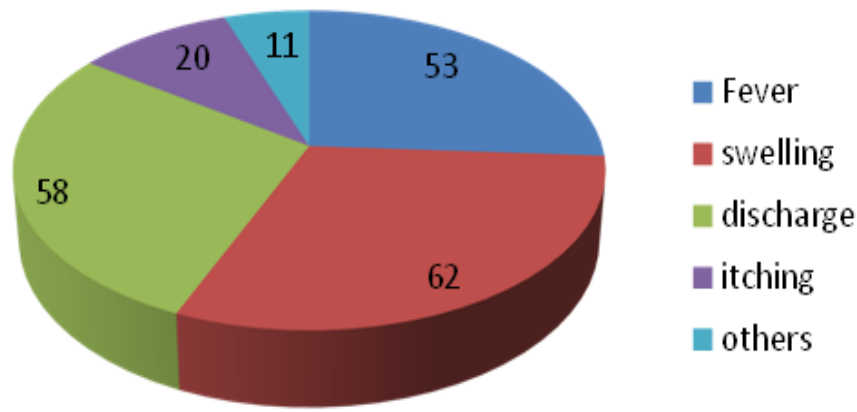

\begin{tabular}{|l|l|l|l|l|}
\hline $\begin{array}{l}\text { Type of skin } \\
\text { infection }\end{array}$ & Cases Total & healthy & $\begin{array}{l}\text { Infecte } \\
\text { d }\end{array}$ & $\begin{array}{l}\text { Exp } \\
\text { ired }\end{array}$ \\
\hline $\begin{array}{l}\text { Boil/furuncle } \\
\text { Carbuncle }\end{array}$ & 15 & 12 & 2 & 1 \\
\hline Cellulitis & 21 & 13 & 8 & 0 \\
\hline Diabetic foot ulcers & 12 & 11 & 1 & 0 \\
\hline Candidiasis & 26 & 20 & 4 & 3 \\
\hline Dermatophytes & 4 & 3 & 1 & 0 \\
\hline Gangrene & 3 & 3 & 1 & 0 \\
\hline Foniers gangreen & 1 & 1 & 2 & 0 \\
\hline $\begin{array}{l}\text { Malignant otitis } \\
\text { externa }\end{array}$ & 3 & 1 & 0 & 0 \\
\hline Mucormycosis & 1 & 3 & 0 & 0 \\
\hline Herpis Zoster & 1 & 0 & 0 & 1 \\
\hline Necrotising fascitis & 4 & 1 & 0 & 0 \\
\hline
\end{tabular}

Table 5 Anaemia

\begin{tabular}{|l|l|l|l|}
\hline Hb (gm\%) & Cases & Controls & P value \\
\hline$<8$ & 12 & 0 & \\
\hline $8-11$ & 50 & 14 & $<0.05$ \\
\hline $11-13$ & 29 & 31 & \\
\hline$>13$ & 9 & 5 & \\
\hline
\end{tabular}


Table 6 Corelation of Leococytosis with Wound status

\begin{tabular}{|l|l|l|l|l|}
\hline WBC & Healthy & Infected & Expired & Total \\
\hline$<4000$ & 0 & 0 & 0 & 0 \\
\hline $4000-10999$ & 7 & 2 & 1 & 10 \\
\hline $11000-20000$ & 24 & 8 & 0 & 32 \\
\hline$>20000$ & 40 & 14 & 4 & 58 \\
\hline
\end{tabular}

Table $7 \mathrm{HbA1c}$ levels

\begin{tabular}{|l|l|l|}
\hline HbA1c & Cases & Controls \\
\hline$<6.5$ & 0 & 5 \\
\hline 6.5 to 7.4 & 21 & 45 \\
\hline 7.50 to 8.9 & 48 & 0 \\
\hline 9 to910.9 & 17 & 0 \\
\hline 11 to12.9 & 10 & 0 \\
\hline$>13$ & 4 & 0 \\
\hline Total & 100 & 50 \\
\hline
\end{tabular}

Table 8 Culture from wound swab

\begin{tabular}{|l|l|l|}
\hline Organism & Number \\
\hline No growth & 60 \\
\hline Staph & MSSA & 5 \\
\hline Acinatobactor & MRSA & 12 \\
\hline Pseudomonas & & 6 \\
\hline Candida & 2 \\
\hline E. coli & 2 \\
\hline Klebsiella & 6 \\
\hline
\end{tabular}


Table $9 \quad$ Association with systemic complications

\begin{tabular}{|l|l|l|l|l|}
\hline Wound & Retinopathy & Nephropathy & Neuropahy & PAD \\
\hline Healthy & 13 & 4 & 21 & 12 \\
\hline Infected & 7 & 1 & 7 & 3 \\
\hline expired & 1 & 0 & & \\
\hline
\end{tabular}

Table 10 Corelation of $\mathrm{HbA} 1 \mathrm{c}$ with wound status and morbidity

\begin{tabular}{|l|l|l|l|l|}
\hline HbA1c & Healthy & infected & expired & P value \\
\hline$<5.6$ & 0 & 0 & 0 & \\
\hline $5.6-6.5$ & 15 & 4 & 2 & \\
\hline $6.6-8.9$ & 34 & 12 & 0 & $<0.05$ \\
\hline $9-10.9$ & 14 & 3 & 2 & \\
\hline $11-12.9$ & 5 & 4 & 0 & \\
\hline Total & 71 & 1 & 5 & \\
\hline
\end{tabular}

\section{Table 11 Duration of in hospital stay}

\begin{tabular}{|l|l|l|l|l|}
\hline Duration & $\begin{array}{l}\text { No. of } \\
\text { cases }\end{array}$ & Healthy & infectd & Expired \\
\hline OPD & 9 & 9 & 0 & \\
\hline$<$ days & 28 & 16 & 11 & 1 \\
\hline $7-14$ days & 43 & 35 & 7 & 1 \\
\hline $15-28$ days & 14 & 10 & 3 & 1 \\
\hline$>28$ days & 6 & 2 & 2 & 2 \\
\hline
\end{tabular}


Fig 1 Distribution of cutaneous infections in various parts of body

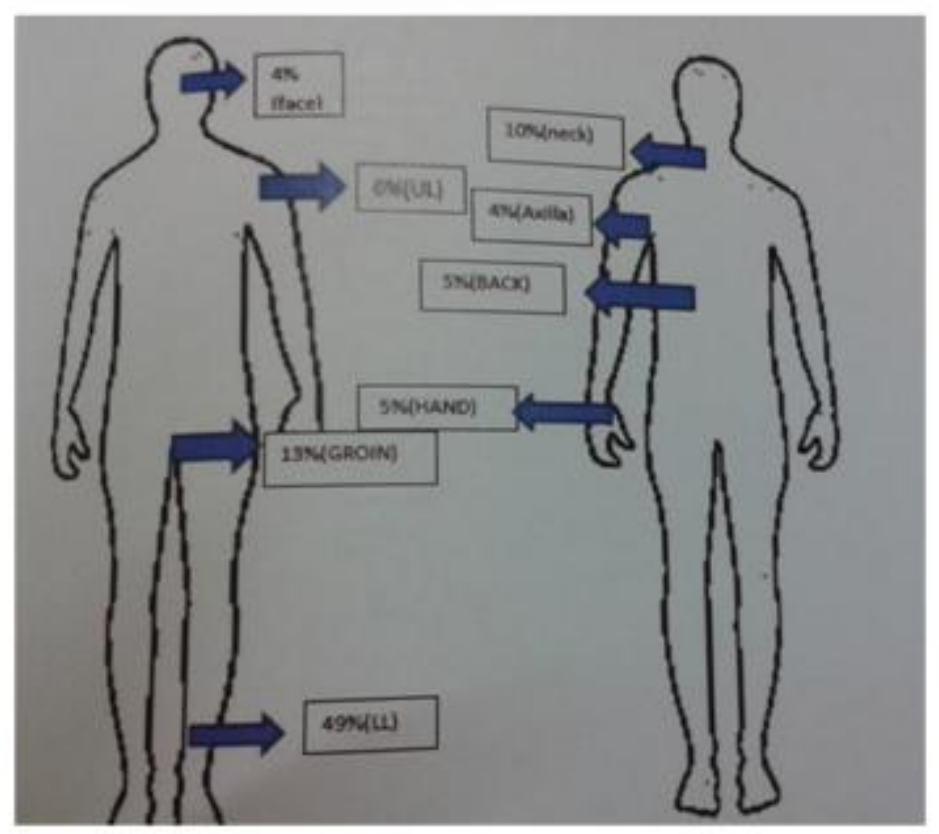

